\title{
Integrating the world of presence theory: Illusion, pretence, attending, and pretending \\ John Waterworth ${ }^{1}$ and Ingvar Tjostheim² \\ ${ }^{1}$ Umeå University, Umeå, Sweden (john.waterworth@umu.se) \\ ${ }^{2}$ Norwegian Computing Center, Oslo, Norway2
}

Notes:

1. Corresponding author: John Waterworth, Umeå University, 90187 Umeå, Sweden

2. A version of this paper appears in the Proceedings of Presence 2020, 18th conference of the International Society for Presence Research (ISPR) 


\begin{abstract}
We selected four fragments from the world of presence theory for particular attention. These are: presence as a perceptual illusion, as a pretence, as attending to an external world, and as pretending the virtual is real. We reflect on and try to unite these fragments into a fairly coherent and perhaps more general view of the nature of presence, one that may help integrate insights into both 'natural' and mediated presence. One conclusion from this work is that when we feel present, we believe that what is happening is real, in the moment, whether it is in the physical world or in a virtual reality (VR). In other words, when we feel really present in an environment it is real for us. If presence in VR is an illusion, so is presence in the physical world. Presence in VR requires imagination and belief (though not make-believe), and so does presence in the physical world.
\end{abstract}

Keywords: Spatial presence, illusion, pretence, attending, belief, make-believe, imagination, metaphor. 


\section{Introduction}

We start the paper by providing a brief overview of several different theoretical views of the nature of spatial presence. From that, we select four fragments from the world of presence theory for particular attention. Briefly stated these are: presence as a perceptual illusion, as a pretence, as attending to an external world, and as pretending the virtual is real. These are very different views of presence which we chose for their popularity (their level of general acceptance as serious accounts by the presence research community) and their power and scope to explain important aspects of the presence experience, as well as our aims in this paper.

Our aims are i) to reflect on and if possible, to unite these fragments into a more coherent and general view of the nature of presence, and ii) to use this united view to integrate insights into 'natural' and mediated presence. Our underlying interest is the presence experience, what it is, under whatever conditions it occurs.

Many theorists agree with our view that presence can be experienced in the physical or material world, as well as in mediated environments. The latter class of experiences is often referred to as telepresence or mediated presence. Many give the former-presence in the physical world - a special status, on the assumption that a mind-independent external reality exists. Manzotti \& Pepperell (2012: 6) write: "Our access to the world is understood, to a greater or lesser extent, to be direct rather than mediated, representational or illusory." A key question for presence theorists is how, and if, 'natural presence', as an experience, is different from mediated presence.

\subsection{A brief overview of presence theories}

In Table 1 we present selected definitions of telepresence from the 1980s and 1990s, highlighting some key words for our present purpose. 
Table 1 - Some early definitions of presence

\begin{tabular}{|c|c|}
\hline Akin et al. (1983) & $\begin{array}{l}\text { The word telepresence means remote presence.... At the worksite, } \\
\text { the manipulators have the dexterity to allow the operator to perform } \\
\text { normal human functions. At the control station, the operator } \\
\text { receives sensory feedback of sufficient quantity and quality to } \\
\text { provide a feeling of actual presence at the worksite. }\end{array}$ \\
\hline Sheridan's (1986) & $\begin{array}{l}\text { (Telepresence means) "visual, kinesthetic, tactile or other sensor } \\
\text { feedback from the teleoperator to the human operator that is } \\
\text { sufficient and properly displayed such that the human feels that he is } \\
\text { present at the remote site, and that the teleoperator is an extension } \\
\text { of his own body." }\end{array}$ \\
\hline Steuer (1992) & $\begin{array}{l}\text { "the extent to which one feels present in the mediated } \\
\text { environment, rather than in the immediate physical environment." }\end{array}$ \\
\hline $\begin{array}{l}\text { Lanier and Biocca } \\
(1992: 156)\end{array}$ & $\begin{array}{l}\text { Presence consists of the sensation of being in a certain } \\
\text { environment" (i.e., the perception of being inside a collection of pre- } \\
\text { existing extra-mental objects); telepresence is "the experience of } \\
\text { being in an environment thanks to a means of communication" }\end{array}$ \\
\hline Bates (1992) & $\begin{array}{l}\text { One of the keys to an effective virtual world is for the user to be able } \\
\text { to "suspend disbelief." That is, the user must be able to imagine that } \\
\text { the world portrayed is real, without being jarred out of this belief by } \\
\text { the world's behavior. }\end{array}$ \\
\hline $\begin{array}{l}\text { Slater and Usoh } \\
\text { (1993) }\end{array}$ & $\begin{array}{l}\text {....presence in an IVE involves the commitment of the person's entire } \\
\text { neurology to the "suspension of disbelief" that they are } \\
\text { "somewhere else" rather than where their physical body really is... }\end{array}$ \\
\hline $\begin{array}{l}\text { Lombard and } \\
\text { Ditton (1997) }\end{array}$ & $\begin{array}{l}\text { "An illusion of non-mediation occurs when a person fails to } \\
\text { perceive or acknowledge the existence of a medium in his/her } \\
\text { communication environment and responds as he/she would if the } \\
\text { medium were not there." }\end{array}$ \\
\hline $\begin{array}{l}\text { Draper et al. } \\
(1998)\end{array}$ & $\begin{array}{l}\text { "A mental state in which a user feels physically present within the } \\
\text { computer-mediated environment." }\end{array}$ \\
\hline Riva (1999: 91) & $\begin{array}{l}\text { "the key issue for developing satisfying virtual environments is } \\
\text { measuring the disappearance of mediation, a level of experience } \\
\text { where the VR system, and the physical environment disappear from } \\
\text { the user's phenomenal awareness." }\end{array}$ \\
\hline Slater (2002) & $\begin{array}{l}\text { "the total response to being in a place, and to being in a place with } \\
\text { other people. The 'sense of being there' is just one of many signs of } \\
\text { presence." }\end{array}$ \\
\hline
\end{tabular}

Somewhat more recent definitions of presence are presented in Table 2 . The term perception plays a more prominent role, and we notice the words sensory and action occurring frequently. 
Table 2 - More recent definitions of presence

\begin{tabular}{|c|c|}
\hline Heeter (2003) & $\begin{array}{l}\text { Presence is contextual. Presence is a series of movements when } \\
\text { cognition and perceptual reactions are closely tied to current } \\
\text { sensory impingements. Presence occurs during periods of time when } \\
\text { cognition (process such as perception, attention, learning, thought } \\
\text { and affect ....) is closely tied to current perceptual stimuli." }\end{array}$ \\
\hline Lee $(2004: 37)$ & $\begin{array}{l}\text { Presence is a "psychological state in which virtual (para-authentic or } \\
\text { artificial) objects are experienced as actual objects in either sensory } \\
\text { or nonsensory ways." }\end{array}$ \\
\hline $\begin{array}{l}\text { Sanchez-Vives } \\
\text { and Slater (2005) }\end{array}$ & $\begin{array}{l}\text { Telepresence is the propensity of people to respond to virtually } \\
\text { generated sensory data as if they (that is what is visualized) were } \\
\text { real. }\end{array}$ \\
\hline Floridi (2005:661) & $\begin{array}{l}\text { The new model shifts the perspective from an internal and } \\
\text { subjective assessment of a peculiar experience - presence as } \\
\text { epistemic failure - to an external and objective evaluation - presence } \\
\text { as successful observation. }\end{array}$ \\
\hline $\begin{array}{l}\text { Wirth et al. } \\
\text { (2007) }\end{array}$ & $\begin{array}{l}\text { Spatial Presence is regarded as a two-dimensional construct. The } \\
\text { core dimension is the sensation of being physically situated within } \\
\text { the spatial environment portrayed by the medium ("self-location"). } \\
\text { The second dimension refers to the perceived possibilities to act. }\end{array}$ \\
\hline Riva (2011: 25) & $\begin{array}{l}\text { Presence is "the intuitive perception of successfully transforming } \\
\text { intentions into action" }\end{array}$ \\
\hline $\begin{array}{l}\text { Waterworth et al. } \\
\text { (2015: } 36 \text { and } 48 \text {; } \\
\text { 2020: } 74)\end{array}$ & $\begin{array}{l}\text { "We define presence as the feeling of being located in a perceptible } \\
\text { external world around the self". "Varying feelings of presence reflect } \\
\text { the extent to which attention is focused on the external } \\
\text { environment". }\end{array}$ \\
\hline Turner (2014) & $\begin{array}{l}\text { Mediated presence as pretending. "We propose that make-believe } \\
\text { is a plausible psychological mechanism which underpins the } \\
\text { experience of mediated presence". }\end{array}$ \\
\hline
\end{tabular}

Below we focus on four different views of what presence is, selected from those above, which we consider to be serious contenders in the field. Another reason for choosing these four views is that we think they raise interesting issues, for example, the meaning and role of illusions, the plausibility of suspension of disbelief, and of the value and significance of the accuracy of simulated experience in relation to presence experiences. They all are principally theories of what is known as physical presence, which we see as the fundamental, the core aspect of presence experiences. We chose not to look more broadly at some other important formulations, such as presence as action (or of the perception of being able to act) and 
presence as the execution of intentions, because we these views can be seen as following from spatial presence experiences - of the surrounding reality in which we feel ourselves to be.

A guiding insight for our work is that mediated presence (or telepresence) in a convincing VR and the feeling of being present in the physical (or actual) world are fundamentally similar, if not the same. This leads us on to hope that not only can an understanding of physical presence help us to understand mediated presence, but also that successful models of mediated presence can help us understand the nature of experiences of the world.

One of the most influential philosophers of the twentieth century, Merleau-Ponty (1962: 408), writes:

"I am conscious of the world through the medium of my body" (1962:94-95). It is from the body that I perceive the world. Without a body, I have no place from which to perceive the world. "Where is" begins with the location of the body. It locates me in a place." [....] "my existence as subjectivity is merely one with my existence as a body and with the existence of the world, and because the subject that I am, when taken concretely, is inseparable from this body and this world".

By examining the strength and weaknesses of different theoretical accounts of presence, our aim is to derive a composite view that is more comprehensive in its explanatory scope than any of these (or other) views in isolation. 


\section{Four fragments of presence theory}

In this second section, we outline what we see as four important fragments of presence theory. Each has contributed to our understanding of presence, but none provides a completely adequate explanation of this complex phenomenon.

\subsection{Presence as the illusion of non-mediation}

One of the most highly cited definitions of presence is the one by Lombard and Ditton (1997). They conceptualize telepresence as a kind of illusion, the perceptual illusion of non-mediation. Therefore, they regard (tele)presence as a property of a person. It results from an interaction between formal and content characteristics of a medium and characteristics of the media user, and therefore it can and does vary across individuals and across time for the same individual. However, they do not explain or discuss the use of the term "illusion", which can have more than one interpretation.

In the same vein, to Riva (1999:91) "the key issue for developing satisfying virtual environments is measuring the disappearance of mediation (our emphasis), a level of experience where the VR system and the physical environment disappear from the user's phenomenal awareness." This is a an almost ubiquitous and very influential view of presence, resonating with the blind man's cane example of Merleau-Ponty (1962) and the notion transparency in $\mathrm{HCl}$. The blind man walks down the street, exploring the world with his cane. He is not primarily aware of the cane, but of what he perceives with its active use. In the context of telepresence and mediated presence, the medium (the display and the input devices) correspond to the cane. The VR technology disappears for the perceiver, and becomes part of the here-body experience (Ihde, 2002).

\subsection{Presence as pretence (a "simulated semblance")}

Mel Slater suggested (Slater, 2003) that we need different words for the different meaning of presence used by various researchers. What he means by presence could, perhaps more 
accurately, be labels pretence. According to one definition in Webster's online dictionary, this means: "An artful or simulated semblance". A key point is that by using the word "pretence" here, Slater is suggesting that the VR, the simulation, is pretending to be the corresponding place in the physical word. Earlier (Slater, 2002) had defined presence as: "the total response to being in a place, and to being in a place with other people. The 'sense of being there' is just one of many signs of presence - and to use it as a definition or a starting point is a category error: somewhat like defining humour in terms of a smile" (p. 7).

Slater (2003) indicates that the more the immersant has the same total response as would be the case in the physical world, the higher the degree of experience presence. For Slater, presence seems to be about form, not content. It should not be confused with degree of interest in, nor emotional engagement with, the contents of an environment.

\subsection{Presence as attending to an external world}

Our own view of presence is that it is a feeling that arises from more attention being to the world surrounding the body, as compared to attention directed to the world of thoughts and other internal mental constructions (Waterworth \& Riva, 2014; Waterworth \& Waterworth, 2001, 2003, 2006; Riva et al., 2004, 2011, 2015; Waterworth et al., 2010; 2015, 2018, 2020). As Waterworth et al. (2020: pages 67-88) put it: "A well-calibrated sense of presence is needed so that we can identify when and to what extent we are dealing with internal representations of past, possible future, or imaginary events as compared to when we are dealing with current events actually happening in our present environment. When we focus more on the former, we are mentally absent from the world to some extent and experience a low level of presence in our environment, whereas focusing more on the latter - on concrete rather than abstract information - is accompanied by a stronger feeling of presence. Recognition of this absencepresence dichotomy is an important step in understanding of what presence is for, and therefore what it can potentially do". 
From this theoretical perspective, an external world - whether mediated or not - will give rise to a sense of presence, of being present in that world, in direct proportion to the extent to which the individual pays attention to that world. We agree with Slater (2003) that it is important to distinguish presence from emotional engagement, otherwise the concept of presence will lose any distinctive meaning but emotional engagement will have an impact on presence, through its effect on attentional selection.

\subsection{Presence as pretending}

In a series of interesting and provocative publications. Turner and his colleagues argue for the importance of belief to real world presence and of pretending (to believe) or make-believing, to computer-mediated presence. Sometimes these authors use the word "pretence" to mean a pretend situation - a situation whose conjuring requires pretending - not in Slater's use of the word to mean "simulation".

Turner et al. (2014: 1) suggest that: "A principal, but largely unexplored, use of our cognition when using interacting technology involves pretending. To pretend is to believe that which is not the case, for example, when we use the desktop on our personal computer we are pretending, that is, we are pretending that the screen is a desktop upon which windows reside. But, of course, the screen really isn't a desktop".

Turner (2016b) states that when we play a computer game "we temporarily believe that we are killing aliens". At some reflective level we know we are not killing aliens, of course, but we have the vivid experience that we are (thanks to the game technology and media content). This is presence seen as the experiential illusion of non-mediation - but is it pretending? Pretending seems to be characterised by not believing, not by the temporary belief that a mediated experience is real. We return to this issue in Section 4. 


\section{Presence and perceptual illusions}

In this section we examine the nature of perceptual illusions a bit more closely, given that - on the face of it at least - most of the above accounts of presence can be understood as seeing it as resulting from some form of illusion. The concept of illusion is closely related to that of belief. To the best of our knowledge, Turner is the only theorist to discuss belief, which we see this as another key concept for a more general understanding of the characteristics of presence.

\subsection{Views on illusions}

There are a number of different accounts of perceptual illusions. The psychologist Osvaldo Da Pos $(1996,1997,2008)$ distinguished between two kinds. The first are the psychophysical illusions that are discrepancies between what we perceive, for example redness, and the physical, not perceivable variables, for example wavelength, which are known to be correlated (Da Pos, 1997: 37). The second are the phenomenological illusions. These are discrepancies within the phenomenal world. When these occur, the same perceived object appears at one time with some characteristics and at another time with different characteristics.

According to Reynolds (1988) the psychological concept of illusion can be defined as a process involving an interaction of logical and empirical considerations. Common usage suggests that an illusion is a discrepancy between one's awareness and some stimulus. (Reynolds, 1988:) After proposing and rejecting five definitions of illusion based on this usage, he redefines illusion without reference to truth or falsity, as: "a discrepancy between one's perceptions of an object or event observed under different conditions." (Reynolds, 1988: 217). 

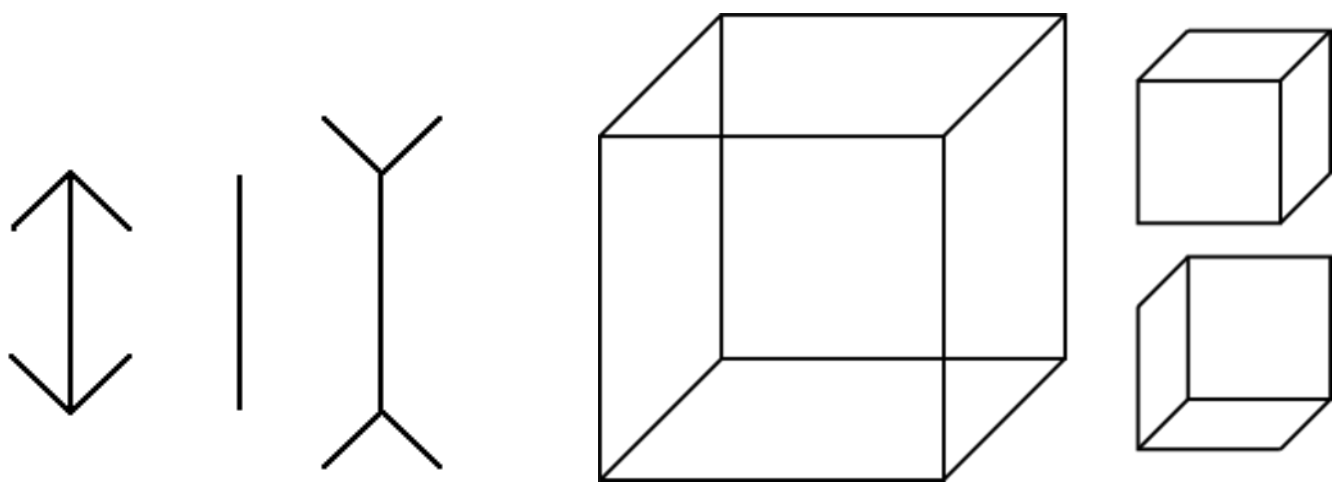

Figure 1 - The Müller-Lyer Illusion and the Necker Cube (public domain images)

Byrne (2009) argued that there is no direct path from the persistence of illusion to the beliefindependence of experience. To him, the Müller-Lyer illusion (see Figure 1) involves a belief that one line is longer than the other, and another, more reflective belief that they are of the same length. This is relevant to the way presence may work; we may know, reflectively, that what we experience in a VR is not really happening, but our experience is that it is and, in the moment of experiencing, we may actually believe that it is happening.

Turner (e.g. 2016a) makes the same point, although he equates mediated presence with makebelieving, with pretending to believe, rather than actually believing - which reduces the coherence of his position, unless we are pretending to experience an illusion. Turner and colleagues state that make-believe "is a form of cognition which is decoupled from the real world and which enables us to explore and engage with fictional or imaginary worlds" (Turner et al., 2014).

Voss et al. (2011) posit the notion of the spectator as surrogate body. The word Leihkörper literally means "loan body." This concept emphasizes the basic structure of illusion that informs the cinematic experience. Voss et al. argue that cinema is an illusion-forming medium and that cinematic illusion emerges from the spectator's engagement with the virtual or loan body of the film. Their thesis is that it is "only the spectator's body, in its mental and sensorial-affective resonance with the events on-screen, which "loans" a three-dimensional body to the screen 
and thus flips the second dimension of the film event over into the third dimension of the sensing body (2011:145). Voss and her colleagues build on Michael Polanyi's (1966) work on the tacit dimension.

\subsection{An example: the sinister watcher}

Imagine that you are out late at night, walking alone, taking a short-cut to get home. It is dark and there seems to be no-one else around. Your walk takes you through a particularly secluded area, perhaps a path through some woods, across a park, or down dark and deserted streets. You wanted to get home quickly, so you chose this route. But now you start to feel afraid. You see what looks like the figure of a person in the middle distance, difficult to see clearly in the darkness. You know that you have to walk close to this figure to get home. As you get closer, you get the clear impression that the person you first saw vaguely from the distance is watching you, and perhaps waiting for you to get nearer. You start to feel afraid and already you feel very present in that environment - much more so than when you first saw "the watcher". You are acutely aware that you have no other way home, except to pass the figure or turn and retrace your steps - which would take a long time (and mean turning your back on the potential danger. You draw closer, ever more convinced that the figure is watching you, and that he or she has a sinister intent. Still, you press on, heart beating fast and acutely aware of your presence in this place, with this person. Suddenly, as you get quite close to the figure, you realise that it is not, in fact, a person at all! It is a misshapen, sawn-off tree trunk and empty crate, with an old paper sack that has somehow come to be attached to the top. You relax, you walk on breathing more deeply and calmly, laughing at your own mistake, which you replay in your mind. You will your friends about this funny episode when you get home- You no longer feel afraid, or very present in the place. See Figure 2 for an artistic interpretation of this kind of shifting perception. 


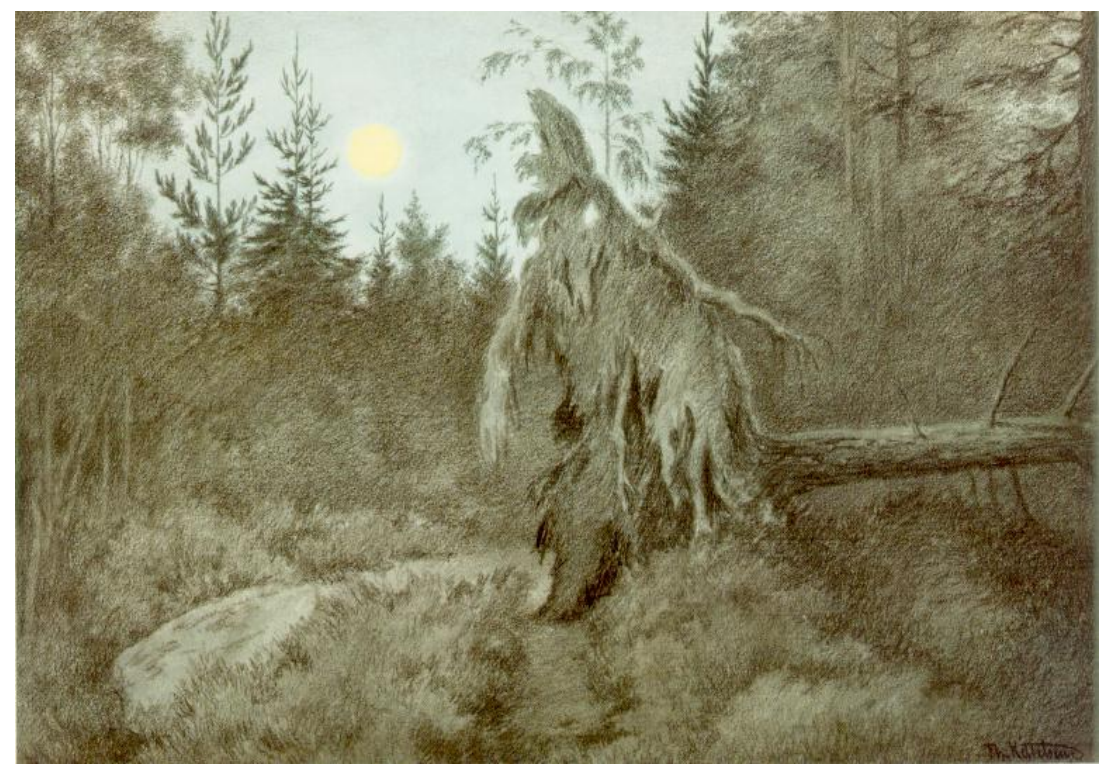

Figure 2 - Theodor Kittelsen - Det rusler og tusler rasler og tasler, 1900

(Creepy, Crawly, Rustling, Bustling; public domain image)

This story of the sinister watcher, who wasn't actually there, illustrates how we can readily misperceive our environment, seeing it in different ways at different times, and that this can have profound effect on our sense of presence, of being there. In this example, high presence results from a misperception - an illusion. But that is not to say that presence is an illusion, it could equally be the case that the presence-inducing perception turned out to be the true one. 


\section{Reflections on the fragments}

In this section we evaluate the theoretical positions outlined above, emphasising the common ground and complementarities between them. We go on in the following section to conclude with a suggested partial integration based on a re-interpreted version of our own account of presence and some general observations.

\subsection{Presence as perceptual illusion}

"Illusions are a phenomenon easily described within a representational model of perception. Any time our knowledge doesn't accurately model its referent we say things are not as they "seem" to us" (Allsop, 2010:199).

Lombard and Ditton's (Lombard \& Ditton, 1997) well-accepted description of presence is appealing, but the argument concerning the inadequacy of pretence, above, points to its limitations. It is essentially a formulation of presence as "being there". We perceive we are in a place without being distracted by the mediating technology, which has become transparent. While we agree that we do need to have the convincing experience that we are "there", it is a necessary but not sufficient requirement for presence. This concerns the process that takes place (in the feeling of being there).

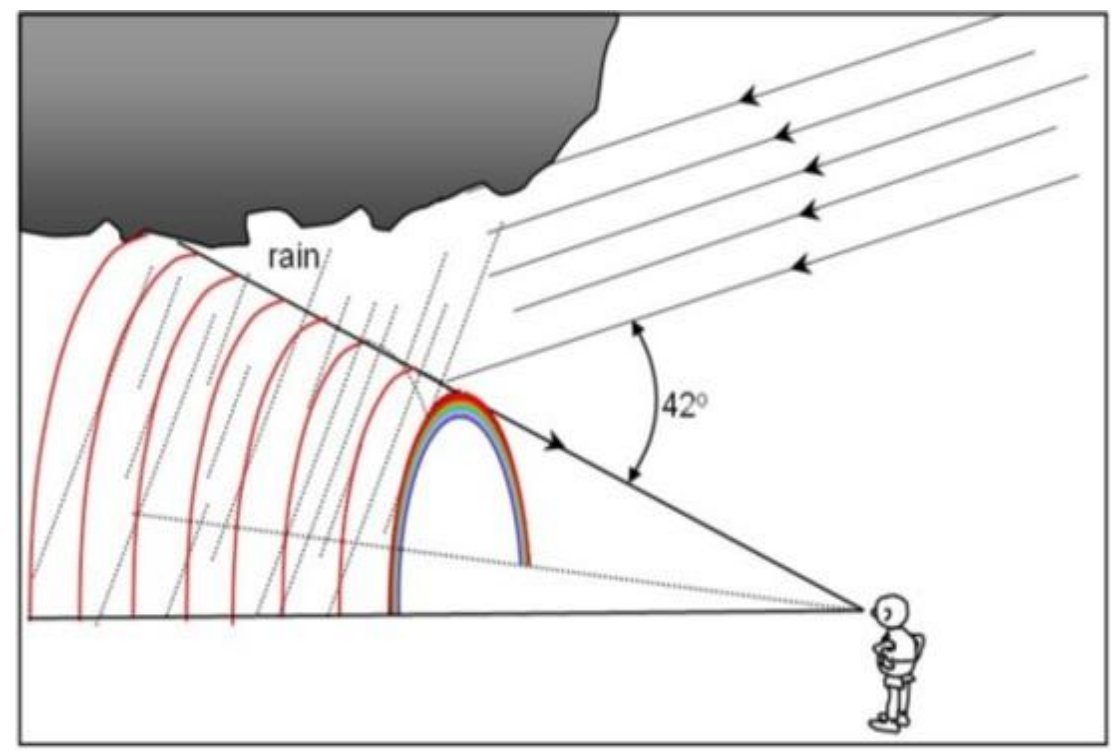

Figure $3-\mathrm{A}$ rainbow is real to the observer (image in the public domain) 
A rainbow is perhaps the best example of a situation where the distinction between the observed object/event and the observing object/event is not evident (see Figure 3). Manzotti (2006) explains it as follows: the rainbow is something that cannot be defined in any meaningful sense independently of an observer and the point of view from which it is seen. In this sense, the rainbow as a unity, although constituted by a series of physical drops of water in space reflecting the light in a certain way, cannot be defined without knowing where and how it will be seen. For instance, it is not possible to fly under a rainbow or to sidestep it. Furthermore, a rainbow is a private but physical phenomenon. The rainbow is not there to be perceived. The rainbow is a process that requires particular weather conditions as well as in the observer's brain and body. The existence of the rainbow depends not only on the presence of the necessary physical conditions and the observer, but on a physical continuity between the two. A If a rainbow is not really "there" to be perceived; is it an illusion? We think not really.

\subsection{Pretending, belief and metaphor}

We agree with Turner's view that presence is a feature of experience of both the unmediated world and some computer-mediated environments. We also follow his line of reasoning when he suggests that belief plays a role for presence in both. But we see belief not as a pre-requisite, but as a consequence. The old saying "seeing is believing" can be rephrased as presence is believing - when we feel present in a world, it is real for us in that moment. We believe it to be the case in the here and now of experience, without pretending to. The essence of pretending seems to us to be that, even when pretending, we know that what we are pretending is happening is not. It is not an illusion, it is a pretence. When we feel presence, we may know (at some level) that the experience is not based on the body being where it is felt to be, but we do not need to pretend to experience it is real.

Turner (2016b) says (for example) that when we play a computer game "we temporarily believe that we are killing aliens". We can accept this use of "belief"- in fact, we agree with it - because in the moment in a convincing VR, the act is real for us (even though at some more cognitive 
level we still know we are not killing aliens). We have the experience that we are (thanks to the game technology and the media form and content). That is presence; it can be seen as the experiential illusion of non-mediation, but it is not pretending. We do not pretend we are killing aliens or to believe we are having the experience of killing them. Because we feel present we don't have to. Another example, frequently-cited, is the children's make-believe or play "tea party". But if we were pretending we would not believe we were at a tea party; if we did believe we would not be pretending.

We differ from Turner also about the relationship between imagination and metaphor, and how this relates to presence. In several publications Turner and associates (Turner et al., 2014; 2015; Turner, 2016b) have put forward the idea that often interfaces are metaphorical but that we pretend that they are real. They suggest that, since metaphor clearly involves imagination, imagination is needed to make sense of interactions and of presence. We make-believe mediated environments are real and thus imagine their meaning. When we imagine, we think, we reflect, and from a dual-process theory point of view, this is system 2 type process (Evans, 2003).

But, by our view, when we feel truly present in such an environment, we interact in a direct way - say when shooting a simulated enemy with a digital gun. We do not need to make-believe, pretend or use our imaginations (to make it real). For us, like the physical world usually is, it is real in the moment. And yet, it also has metaphorical aspects to its meaning - as does the physical world - along the lines of Lakoff and Johnson's cognitive realism (Johnson, 1987; Lakoff, 1987; Lakoff \& Johnson, 1980), but applied to perceptions of the world - not only making sense of more abstract conceptions. In this sense, metaphor does not imply the use of imagination. Imagination implies the use of metaphor.

Turner's position gains some support from findings indicating that user characteristics, such as expressed willingness to experience presence in a VE, affect the level of presence reported (e.g. Cummings \& Bailenson, 2016; Sas \& O'Hare, 2003). Sas and O'Hare (2003) explicitly suggest that 
presence can arise in response to imagined worlds, but they also conclude that "the more users think, feel and act in the remote world [......] the greater the sense of presence they will experience" (page 535). This seems contradictory, since action is not possible in imagination; indeed a main function of imagination is to test possible actions (including their emotional effects) without carrying them out (Damasio, 1999).

We suggest that Sas and O'Hare (2003) are referring to the more general concept of absorption: a characteristic of the individual that involves an openness to experience emotional and cognitive alterations across a variety of situations (Roche \& McConkey, 1990), including both those that give rise to presence and those that result in a feeling of absence. Both high presence and intense absence are absorption states, the former based around the current perceptual flow, the latter around imagined events and situations.

Turner (2016a, b) also argues for presence as make-believe from a system 2 point of view (Evans, 2003); in other words, as a result of relatively slow and deliberative thinking. But this contradicts the idea that presence arises in situations where fast and instinctive bodily responses (from a type-1 cognitive process) are called for, for example in a fast-paced computer game. As Waterworth and Riva, 2014: 38) describe presence as "the sheer subjective experience of being in a given environment (the feeling of "being there") that is the product of an intuitive experience-based metacognitive judgment".

We understand the world and its possibilities through our bodies, and from the metaphorical projections of embodied image schemata come to give it meaning and make imagination possible. Not only does our body structure meaning. In its relation to the spatial world around it, it also provides an anchor for mental activity. This is how, by interacting with designed technology, we can carry out meaningful activities via bodily actions. The relationship between mind, body and world is mutual and circular. Merleau-Ponty (1962) refers to this feedback loop between the embodied "coper" and the perceptual world as "the intentional arc". 


\subsection{Presence: a successfully simulated semblance?}

We agree with Slater that the level of presence experienced in a mediated environment is heavily dependent on form. We are unlikely to feel much presence in a poorly-rendered VR, perhaps with unrealistic sound and a perceptible lag between our actions and the corresponding events in the world. In the physical world, the form seems to be given, and things behave and respond according to our embodied and largely unconscious expectations. But what of the sinister watcher we met earlier, the one that suddenly transforms into a harmless tree stump? By Slater's view - and it seems to us to be correct - if we accurately reproduce all perceptible aspects of the situation, we will have a similar switch from the sinister watcher to the harmless tree in a VR version of the place. In this case, the form is the same, but it gives rise to two very different experiences. This supports the idea that presence is not only a matter of form.

Slater (1992) defined presence as the total response to being in a place. He recommends triangulating multiple measures to assess the level of presence, such as postural changes, physiological indicators, and verbal reports (though he is not keen on questionnaires!). But his view of presence (e.g. Slater, 1993) suggests not that those indicators in themselves measure presence, but that the level of experienced presence reflects the match between those indicators from a VR experience and a similar situation in the physical world. If presence is the total response to a simulation, as compared to the total response to the physical environment being simulated, then how do we assess presence in virtual environments that convey fictional realities? If no comparison with reality is involved, how can the "total response" be quantified? This view suggests that presence is the degree of similarity with physical reality, not a basic state of consciousness (as suggested by Loomis many years ago; Loomis, 1992).

It seems reasonable that if the form of the physical world can be accurately simulated, we will have the same experiences in the mediated world as in the physical one. And we will have the same level of presence. But that does not imply that the level of presence experienced in a virtual environment is the same as the level of accuracy of the simulation, to how well the 
pretence is executed. When we believe that we are being watched and are under threat, we will feel much more presence than when we do not - but the level of pretence is the same.

\subsection{Attention to the surrounding world: perceptions and misperceptions}

Waterworth et al. (2015: 36 and 48; 2020: 74) define presence as "the feeling of being located in a perceptible external world around the self"; "Varying feelings of presence reflect the extent to which attention is focused on the external environment". Presence is an experience of being in a place, one that allows us to separate the self from the non-self, the internal from the external, a faculty that helps us to survive. According to Waterworth (2008), when the technology producing a world is not a focus of our attention, the technology becomes part of the self, the body. The medium disappears. We do not notice the medium, in the same way that we do not notice the body during perception. It is there, but "ready-to-hand", not always completely transparent, perhaps sometimes semi-transparent. But this is not necessarily the same as experiencing an illusion of non-mediation.

As can be seen in Figure 4, there are hypothesized to be three layers of presence, that have emerged over evolutionary history (Riva et al. (2004). Proto presence arises from movement of the body in an environment and operates primarily through proprioception; core presence is based in immediate perception; while extended presence relates to the significance of events

for the perceiver. Figure 4 presents a view of how the strength and focus of attention gives rise to high presence and high absence states. 


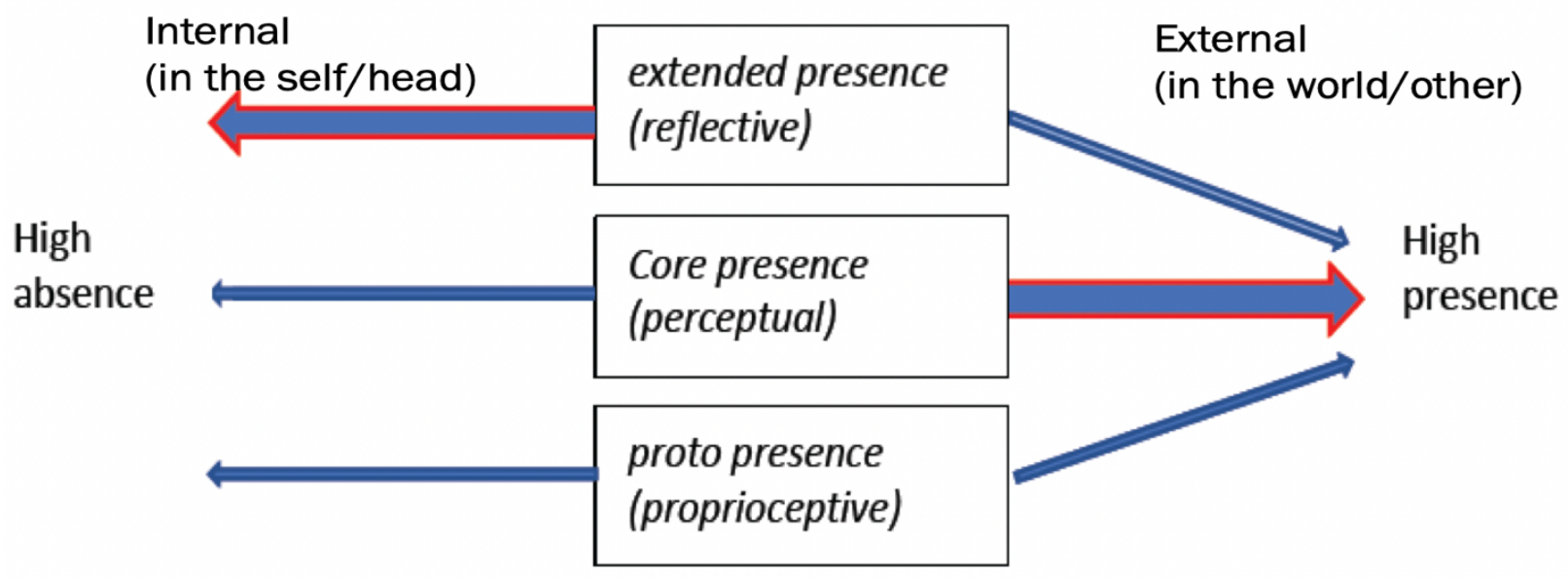

Figure 4 - Strength and focus of attention in high presence and high absence states (adapted from Waterworth et al., 2020; with permission)

Normal, everyday levels of presence arise from a split of attentional resources between layers of differing content, with some attention being directed to the current external situation. Minimal presence results from a lack of integration of the three layers, such that attention is mostly directed towards contents of extended consciousness that are unrelated to the present external environment - a psychological state of absence (Waterworth and Waterworth, 2001). Presence is experienced most strongly when all three layers are integrated and conscious attention is focused on the same external situation, whether this is physical reality, virtual reality, or a mixture of the two (Figure 4). Extended presence corresponds to the extent and way in which top-down processing affects perception of what is happening the outside world.

Maximal presence in a mediated experience arises from an optimal combination of form and content. The form must provide the means for a convincing perceptual experience, but the content should be integrated with (and so attract attention to) the form for this to happen convincingly. Proto presence is determined only by form, core presence by both form and content, and extended presence only by content. The integration of presence can occur in either the real or a virtual world. In the case of a virtual world, we need to provide both appropriate form and meaningful content. Presence in the real world depends only on content 
of that perceived world, on what we experience as happening to us in the here and now, since the form is provided and is always appropriate - though sometimes ambiguous, as illustrated by the "sinister watcher" story.

To integrate extended presence with the other levels, the events and entities experienced in a virtual environment must have significance for the participant. The internal and external are not always competitive for attention. The imaginal content (of extended consciousness) may either enhance or detract from the overall sense of presence. An example of enhancement is a typical computer game, where game designers strive to ensure that content and form are well integrated, or - in the physical world - any situation where we conceive ourselves to be in danger. Optimal presence arises when the contents of extended consciousness are aligned with the other layers of the self, and attention is directed to a currently present external world.

Both mediated and unmediated presence are based in perception, and perception is categorical, though sometimes transitory. A sinister, stooping figure with a black hood, vividly experienced as watching us through twilight mist, suddenly becomes an old, misshapen tree stump as we approach it. It does not gradually morph from one to the other. For a while, we believe in the reality of the sinister watcher; we feel anxious and a chill runs down our spine. A moment later we believe, and know, that the tree stump is what is real in the material world (the Necker Cube is an illusion famous for creating alternating perceptions - see Figure 1). 


\section{Conclusions}

How can we integrate these four different and sometimes quite divergent theoretical perspectives on presence? We suggest that by looking at our experience of presence in the physical world, and at how perceptual illusions work, we can clarify our understanding of mediated presence. Perhaps more surprisingly, by examining presence experiences in mediated environments we can expand our understanding of presence experiences in the physical world.

\subsection{Presence in reality}

Perception (and presence) is partly a matter of hypothesis generation and testing. When we are fearful we tend to see what our fear predicts - as in the case of policemen mistaking a mobile phone, held by a black suspect on a dark street, for a gun. The constructivist theory of Gregory (1970) emphasized the importance of top-down processing to perception. While his view seems exaggerated in light of the clear importance of sensory information to much of perception, when that information is ambiguous our cognition appears to generate hypotheses about what might be out there to guide the perceptual process. According to our three-layer model of presence in the physical world (see Section 4.2, above), this corresponds to the functioning of extended presence. Top-down processing is sometimes important - but it also results in misperceptions. Gregory (1970) used it convincingly to explain how several perceptual illusions work, including the ambiguous Necker cube (Necker 1832) shown in Figure 1.

Presence depends on perception, and here we see the importance of imagination, of top-down processing. In imagination we use metaphorical projection to make sense of what we are perceiving. But as we have suggested, metaphor does not imply the use of imagination. Rather, we suggest that imagination implies the use of metaphor, so that perception - and presence often involves the use of metaphor. This leads us to the conclusion that our experience of the world is metaphorical, in the sense that we project embodied image schemata (Johnson, 1987; Lakoff, 1987; Lakoff \& Johnson, 1980) onto what we pick up as sensations to make sense of them as perceptions. 
The top-down approach to perception of Gregory (1970) is often contrasted with the more bottom-up approach of Gibson $(1966,1972)$. According to Gibson, perception is largely 'built-in'. How we perceive things is driven, bottom-up, by innate structures. Gibson sees how we perceive as having developed over the course of evolution, and this is how we see our capacity for varying levels of presence experience. We resolve this apparent contradiction by viewing the innate structures of perception (Gibson, 1972) as another way of viewing the image schemata of Lakoff and Johnson (Johnson, 1987; Lakoff, 1987; Lakoff \& Johnson, 1980).

How do we distinguish perceptions of the external world (perceptions which may themselves be largely hypothetical mental predictions) from the purely mental constructions that constitute imagined situations and events? In other words, how do we separate the internally realised world from the externally realised world? We see presence as the capacity to make this distinction and which helps us survive in a dangerous world. This is the purpose of presence (see Waterworth et al., 2015, for more details).

Attention to the external is important to presence in the physical world, and it is similarly important for presence in mediated worlds. We also need to believe in what is happening in a world, whether physical or not. In a mediated world, we need to provide a convincing pretence of reality for presence. But we need to attend to that pretence, we need a reason to believe that drives our attention. We are not pretending, except in the sense that, at some level, we know the virtual reality is a simulation. But in the moment, it is real. In the moment we see the sinister watcher, we believe he is real. A moment later, we don't. This is equally true in a VR as in the physical world. Presence can be viewed as sometimes resulting from a perceptual illusion. We need to attend for an illusion to work, but only to the things that make it work. Perception can itself sometimes be illusory.

When we feel present, we believe that what is happening is real, whether in the physical world or a VR. We do not pretend to believe, we do not make-believe as Turner suggests. Pretending is a characteristic of absence, not presence. Pretence is what we do when we pay attention to 
fictional things, and real things too - that we know (believe) are not what we are currently perceiving in the world around our body. The form of the physical world is given, but ambiguous. In VR, we can experience fictional worlds as if they are real - in fact, as real in the moment. We believe in them and do not need to pretend that we do. Believing in the real, inthe-moment existence of something, experienced as being before us, is a characteristic of perception (and hallucinations; Smith, 2002, 2010¹) and of presence.

\subsection{Final words}

We have focused on the individual's sense of physical presence, in virtual and in physical environments, how these can inform each other as viewed through different theoretical lenses, and how this relates to aspects of what is known about perceptual illusions. We have not specifically addressed issues related to social presence or the sense of co-presence in physical, virtual or mixed reality spaces. It is clearly important to look further into these aspects, which are particularly relevant at the present time - when many people are required or choose to meet in a variety of mediated communication spaces instead of the physical world. Future work will be directed towards these issues. The question of which measurements to use, and how to discuss the presence experience with or without drawing attention to the medium are linked to the perspectives and definitions of presence, and this is also a topic for further work. In the remainder of this section we offer a few final words to conclude our theoretical examination of the world of presence theory, and possibilities for integrating the varied views discussed earlier in the paper.

In attempting to unify these differing perspectives on presence, we find ourselves agreeing with the philosopher David Chalmers (2017) who argued that: "...virtual reality is a sort of genuine reality, virtual objects are real objects, and what goes on in virtual reality is truly real.". If we

\footnotetext{
${ }^{1}$ Hallucinations are mere representational states with no mind-independent objects, in some ways at the opposite pole from veridical perception (Sturgeon 2008, 114). Yet an hallucination might be subjectively indiscriminable from a veridical perception, even though it is a bad case - a mental event only (Smith, 2002; 2010).
} 
experience presence, then the environment we are attending to is real to us in the moment, whether mediated or unmediated. Or, conversely, if presence in VR is an illusion, then so is presence in the physical world. Presence in VR involves imagination (though not make-believe), and so does presence in the physical world.

When we feel highly present, we believe in the perceived world in which we experience ourselves to be. In that moment it is real to us. To have that experience, we must be attending to that world. The world may be a simulation, be veridical, be misperceived, or even be an hallucination. In that moment we do not reflect on this question, and so we do not know which it is - but we believe that it is. 


\section{References}

Allsop, B. (2010). Representational Qualia Theory. Journal of Consciousness Exploration \& Research, 1(2).

Chalmers, D. J. (2017). The virtual and the real. Disputatio 9, 309-352 (2017).

Da Pos, O. (1996). Visual illusions and effects' in L. Sivik (ed.) Colour \& psychology (Stockholm, Sweden: Scandinavian Colour Institute).

Damasio, A. (1999). The Feeling of What Happens: Body, Emotion and the Making of Consciousness. San Diego, CA: Harcourt Brace and Co, Inc.

Cummings JJ, Bailenson JN (2016) How immersive is enough? A meta-analysis of the effect of immersive technology on user presence. Media Psychology 19(2):272-309.

Da Pos, O. (1997). Colour illusions' in The Color Science Association of Japan (ed.), AIC Color 97, Kyoto, Japan: The Color Science Association of Japan.

Da Pos, O. (2008). A phenomenological instead of a psychophysical definition of visual illusions, Gestalt Theory, 30 (2): 181-190.

Draper J., Kaber D., and Usher, J. (1998) Telepresence. Human Factors 40(3): 354-375.

Evans, J. (2003). In two minds: dual-process accounts of reasoning. Trends in

Cognitive Sciences 7(10):454-59.

Floridi, L. (2005) The Philosophy of Presence: From Epistemic Failure to Successful Observation, in: Presence. Teleoperators and Virtual Environments 14/6, 656-667.

Heeter, C. (2003). Reflections on a real presence by a virtual person. Presence: Teleoperators and Virtual Environments, 12 (4): 335-345.

Ihde, D. (2002). Bodies in Technology, University of Minnesota Press, Minneapolis.

Gibson, J. J. (1966).The Senses Considered as Perceptual Systems. Boston:Houghton Mifflin.

Gibson, J. J. (1972). A Theory of Direct Visual Perception. In J. Royce, W. Rozenboom (Eds.). The Psychology of Knowing. New York: Gordon \& Breach.

Gregory, R. (1970). The Intelligent Eye. London: Weidenfeld and Nicolson.

Johnson, M. (1987). The Body in the Mind: The Bodily Basis of Meaning, Imagination and Reason: University of Chicago Press. 
Lakoff, G. (1987). Woman, fire and dangerous things: What categories reveal about the mind. Chicago: The University of Chicago Press.

Lakoff, G., \& Johnson, M. (1980). Metaphors we live by Chicago: The University of Chicago Press. Lanier J. and Biocca F. (1992). An insider's view of the future of virtual reality. Journal of Communication, 42:150-172.

Lombard, M., and Ditton, T. B. (1997). At the heart of it all: The concept of presence. Journal of Computer-Mediated Communication 3(2). Available at: http://jcmc.indiana.edu/vol3/issue2/lombard.html

Loomis, J. M. (1992). Distal attribution and presence. Presence, Teleoperators, and Virtual Environments, 1(1), 113-118.

Manzotti, R. (2006b). An Alternative View of Conscious Perception. Journal of Consciousness Studies 13 (6): 45-79

Manzotti, R., and Pepperell, R. (2012). The New Mind: thinking beyond the head. Al \& Society, 24(1): 1-12.

Morie, J. F. (2007). Meaning and Emplacement in Expressive Immersive Virtual Environments (Doctoral dissertation, University of East London).

Merleau-Ponty, M. (1962). Phenomenology of perception (trans. C. Smith,) New York: Routledge (Original work published in 1945).

Murakami, H. (2018). Killing Commendatore, New York: Knopf.

Polanyi, M. (1966). The Tacit Dimension. London: Routledge and Kegan Paul.

Necker, L. A. (1832). Observations on some remarkable Optical Phenomena seen in Switzerland; and on an Optical Phenomenon which occurs on viewing a Figure of a Crystal or geometrical Solid. The London and Edinburgh Philosophical Magazine and Journal of Science, 1 (5) (1832), pp. 329-337.

Reynolds, R. I. (1988). A psychological definition of illusion, Philosophical Psychology, 1: 217223.

Riva, G. (1999). From technology to communication: Psycho-social issues in developing virtual environments. Journal of Visual Languages \& Computing, 10(1): 87-97. 
Roche, M. S., \& McConkey, K. M. (1990). Absorption: Nature, assessment and correlates. Journal of Personality \& Social Psychology, 59(1), 91-101.

Sanchez-Vives, M. V. and Slater, M. (2005). From presence to consciousness through virtual reality. Nature Reviews: Neuroscience 6: 332-339.

Sas C, O'Hare GM (2003) Presence equation: An investigation into cognitive factors underlying presence. Presence: Teleoperators \& Virtual Environments 12(5):523-537.

Sheridan, T. B. (1986). Human supervisory control of robot systems. In Robotics and Automation. Proceedings. 1986 IEEE International Conference on (Vol. 3, pp. 808-812). April, IEEE.

Slater, M. (2002). Understanding Virtual Environments: Immersion, Presence, and Performance. Siggraph 2002 Course Notes (2002).

Slater, M. (2003). A Note on Presence Terminology. Presence-Connect, 3 (3).

Slater, M. and M. Usoh (1992) An Experimental Exploration of Presence in Virtual Environments, Department of Computer Science, QMW University of London.

Slater, M., and Usoh, M. (1993). Representations systems, perceptual position, and presence in immersive virtual environments. Presence: Teleoperators and Virtual Environments 2(3):221-233

Smith, A. D. (2002). The Problem of Perception. Harvard University Press.

Smith, A. D. (2010). Disjunctivism and Illusion. Philosophy and Phenomenological Research, $80(2), 384-410$.

Turner, P. Presence: Is it just pretending?. Al \& Soc 31, 147-156 (2016a). https://doi.org/10.1007/s00146-014-0579-y

Turner P. (2016b) Making-Believe with Technology. In: HCI Redux. Human-Computer Interaction Series. Springer, Cham

Turner, P., Turner, S. \& Carruthers, L. (2014). It's Not Interaction, It's Make Believe. In Proceedings of the 2014 European Conference on Cognitive Ergonomics (ECCE'14). Association for Computing Machinery, New York, NY, USA, Article 22, 1-8. DOI:https://doi.org/10.1145/2637248.2637266 
Turner, P., Hetherington, R., Turner, S. \& Kosek, M. (2015) The limits of pretending, Digital Creativity, 26:3-4, 304-317, DOI: 10.1080/14626268.2015.1091778

Voss, C. (2006). Filmerfahrung und Illusionsbildung. Der Zuschauer als Leihkörper des Kinos, in Kraft der Illusion, hrsg. v. Gertrud Koch und Christiane Voss, München: Fink, S. p. 71-86.

Waterworth, J A (2008). Information technology, the sense of presence, and the evolution of the conscious self. Proceedings of Toward a Science of Consciousness 2008. University of Arizona, Tucson, USA, April 2008.

Waterworth, J. A., \& Riva, G. (2014). Feeling present in the physical world and in computermediated environments. Basingstoke, UK: Palgrave Macmillan.

Waterworth, E. L., \& Waterworth, J. A. (2001). Focus, Locus, and Sensus: The three dimensions of virtual experience. Cyberpsychology and Behavior, 4(2), 203-213.

Waterworth, J. A., \& Waterworth, E. L. (2003). The meaning of presence. Presence-Connect, 3(2). http://www8.informatik.umu.se/ jwworth/perceotual\%20core.html

Waterworth, J. A., \& Waterworth, E. L. (2006). Presence as a Dimension of Communication: Context of Use and the Person. In G. Riva, M. T. Anguera, B. K. Wiederhold \& F. Mantovani (Eds.), From Communication to Presence: Cognition, Emotions and Culture towards the Ultimate Communicative Experience (pp. 80-95. Online:

http://www.emergingcommunication.com/volume88.html). Amsterdam: IOS Press.

Waterworth, J. A., Chignell, M., \& Moller, H. (2020). Age-sensitive well-being support: design of interactive technologies that modulate internal-external attentional focus for improved cognitive balance and behavioral effectiveness. In Technology and health : promoting attitude and behavior change (pp. 67-88). Academic Press. https://doi.org/10.1016/B9780-12-816958-2.00004-6.

Waterworth, J. A, Chignell, M., Moller, H. \& Kandylis, D. (2018). Presence and human development: age-specific variations in presence and their implications for the design of life-enhancing interactive applications. Proceedings of PRESENCE 2018, 18th conference of the International Society for Presence Research (ISPR), Prague, May 21-22. ISBN: 978-09792217-6-7 
Waterworth, J.A., Waterworth, E.L., Mantovani, F., \& Riva, G. (2010). On Feeling (the) Present: An evolutionary account of the sense of presence in physical and electronically-mediated environments. Journal of Consciousness Studies, 17(1-2), 167-178.

Waterworth, J. A., Waterworth, E. L., Riva, G., \& Mantovani, F. (2015). Presence: Form, content and consciousness. In M. Lombard, F. Biocca, J. Freeman, W. IJsselsteijn, \& R. J. Schaevitz (Eds.), Immersed in media: Telepresence theory, measurement \& technology. Springer. ISBN: 978-3-319-10189-7.

Wirth, W., Hartmann, T., Böcking, S., Vorderer, P., Klimmt, C., et al. (2007). A process model of the formation of spatial presence experiences. Media Psychology 9: 493-525. 